\title{
Malignant bowel obstruction: A retrospective clinical analysis
}

\author{
JIA-HONG CHEN, TZU-CHUAN HUANG, PING-YING CHANG, MING-SHEN DAI, \\ CHING-LIANG HO, YEU-CHIN CHEN, TSU-YI CHAO and WOEI-YAU KAO
}

\begin{abstract}
Division of Hematology/Oncology, Department of Medicine, Tri-Service General Hospital, National Defense Medical Center, Taipei 10114, Taiwan, R.O.C.
\end{abstract}

Received August 12, 2013; Accepted September 24, 2013

DOI: $10.3892 / \mathrm{mco} .2013 .216$

\begin{abstract}
Malignant bowel obstruction (MBO) is a disease with a poor prognosis, particularly in patients with advanced bowel or gynecological cancers. Multimodality teatments may be used to relieve the symptoms in patients with $\mathrm{MBO}$; however, there is currently no consensus regarding the optimal treatment and no strong evidence supporting the efficacy of any treatment in improving the quality of life (QOL) and prolonging survival. We conducted a search through our medical center database of cancer registries for MBO cases between January, 1995 and December, 2008 and analyzed the clinicopathological characteristics and association between treatments and prognosis or QOL. The primary type of cancer causing MBO was found to be adenocarcinoma of colon. The overall survival time was found to be significantly higher among patients presenting with MBO as the initial symptom and improved QOL was achieved in patients who received surgical treatment. The mean survival time and the functional status of colorectal cancer patients receiving targeted therapy and chemotherapy were more satisfactory compared with those receiving surgery alone or conservative treatment. Furthermore, for end-stage cancer patients with $\mathrm{MBO}$, hospice care was effective in reducing pain scores and relieving the symptoms of the disease.
\end{abstract}

\section{Introduction}

Malignant bowel obstruction (MBO) is a disease with a poor prognosis, particularly in patients with advanced bowel or gynecological cancers. Although it may occur at any stage, it is most commonly associated with end-stage cancer (1). Retrospective reviews demonstrated that $10-50 \%$ of patients with advanced cancer stage will develop MBO during the course of their disease and suffer from intractable abdominal pain, nausea and vomiting, which result in a poor quality of

Correspondence to: Dr Woei-Yau Kao, Division of Oncology, Department of Medicine, Tri-Service General Hospital, National Defense Medical Center, 325 Cheng-Kong Road, Section 2, Nei-Hu, Taipei 10114, Taiwan, R.O.C.

E-mail:wykao@tpts5.seed.net.tw

Key words: bowel obstruction, cancer life (QOL), mental and emotional problems (2). Multimodality treatments, including surgery, palliative radiotherapy, chemotherapy and total parenteral nutrition formulas, may be used to relieve the symptoms in patients with $\mathrm{MBO}$; however, there is currently no consensus regarding the optimal treatment strategy and no strong evidence supporting the efficacy of any treatment in improving QOL and prolonging survival.

\section{Materials and methods}

Patient records. In order to evaluate the clinical presentation, treatment options and survival of MBO patients, we searched the TSGH database of cancer registries for MBO cases between January, 1995 and December, 2008 and analyzed the clinicopathological characteristics and the association between treatments and prognosis or QOL. The clinical information and diagnostic results were extracted from the medical records, including demographic data, clinical manifestations, physical examination, radiological findings, laboratory results and pathology reports. Non-malignant causes of obstruction, such as adhesions from previous surgery, hernia, volvulus, inflammatory bowel disease, fecal impaction and bowel ischemia were excluded from this study.

Functional status. The change in patients' functional status following treatment was evaluated according to the Eastern Cooperative Oncology Group (ECOG) performance status, with a decrease in the ECOG score reflecting the improvement of the symptoms following treatment. Clinicopathological data from $27 \mathrm{MBO}$ patients (16 males and 11 females) treated in our hospital, with a median age of 69.3 years (range, 36-92 years) were retrospectively analyzed. Survival was calculated with the Kaplan-Meier method and the groups were compared using the log-rank test $(3,4)$.

\section{Results}

Cases. Among the $27 \mathrm{MBO}$ patients, the primary malignant tumors included 15 colorectal cancers, 5 gastric, 2 duodenal, 2 bladder, 1 ovarian, 1 pancreatic and 1 pseudomyxoma peritonei. The MBO patients were classified as the initial symptom (IS) and post-treatment of primary cancer (PT) groups, according to the time of onset of the MBO symptoms. The clinical characteristics of the IS $(n=10)$ and PT groups $(n=17)$ are summarized in Table I. According to the statistical analysis, 
Table I. Malignant bowel obstruction (MBO): Initial symptom vs. post-treatment of primary cancer groups.

\begin{tabular}{|c|c|c|}
\hline \multirow[b]{2}{*}{ Characteristics } & \multicolumn{2}{|c|}{ MBO patient groups } \\
\hline & $\begin{array}{l}\text { Initial symptom } \\
\qquad(\mathrm{n}=10)\end{array}$ & $\begin{array}{l}\text { Post-treatment } \\
\quad(\mathrm{n}=17)\end{array}$ \\
\hline \multicolumn{3}{|l|}{ Age (years) } \\
\hline Range & $45-92$ & $36-85$ \\
\hline Median & 74.1 & 66.5 \\
\hline \multicolumn{3}{|l|}{ Gender } \\
\hline Male & 5 & 11 \\
\hline Female & 5 & 6 \\
\hline \multicolumn{3}{|l|}{ Stage } \\
\hline III & 3 & 6 \\
\hline IV & 5 & 8 \\
\hline \multicolumn{3}{|l|}{ ECOG score } \\
\hline $0-2$ & 5 & 2 \\
\hline $3-4$ & 5 & 15 \\
\hline \multicolumn{3}{|l|}{ Primary cancer } \\
\hline Colorectal & 8 & 7 \\
\hline Other & 2 & 10 \\
\hline \multicolumn{3}{|l|}{ Treatment } \\
\hline Surgery & 7 & 3 \\
\hline Chemotherapy & 3 & 10 \\
\hline \multicolumn{3}{|l|}{ Outcome } \\
\hline Overall RR (\%) & 50 & 17.6 \\
\hline Survival time (months) & 15.92 & 4.15 \\
\hline
\end{tabular}

ECOG, Eastern Cooperative Oncology Group; RR, response rate.

the overall survival time was significantly higher in the IS group compared with that in the PT group ( $\mathrm{P}=0.003$, Fig. 1).

SI group. The clinical characteristics of the IS group are summarized in Table II. Of the 10 patients in this group, 7 underwent surgery, whereas 3 did not receive surgical treatment. The overall survival time of the patients who received surgical treatment was significantly higher compared with that in the no surgical treatment group $(\mathrm{P}=0.022$, Fig. 2). Of the 7 patients who received surgical treatment, 6 exhibited an improvement in the ECOG performance status, although the difference was not statistically significant $(P=0.206)$. There may be a trend indicating that the survival time of colorectal cancer patients receiving surgery and concurrent treatment is higher compared with those receiving surgery alone $(\mathrm{P}=0.538)$; however, the results require further analysis, taking into consideration the severity of the disease, age and number of cases.

PT group. The clinical characteristics of the PT group are summarized in Table III. The mean survival time of the patients in this group was shorter compared with the IS group. The mean survival time of colorectal cancer patients receiving targeted therapy and chemotherapy was longer

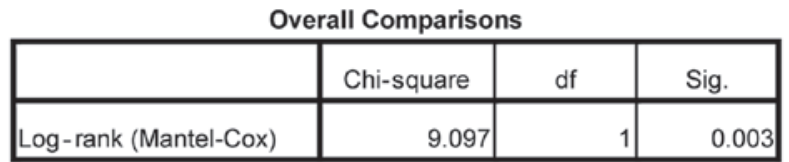

Test of equality of survival distributions for the different levels of group.

Survival functions

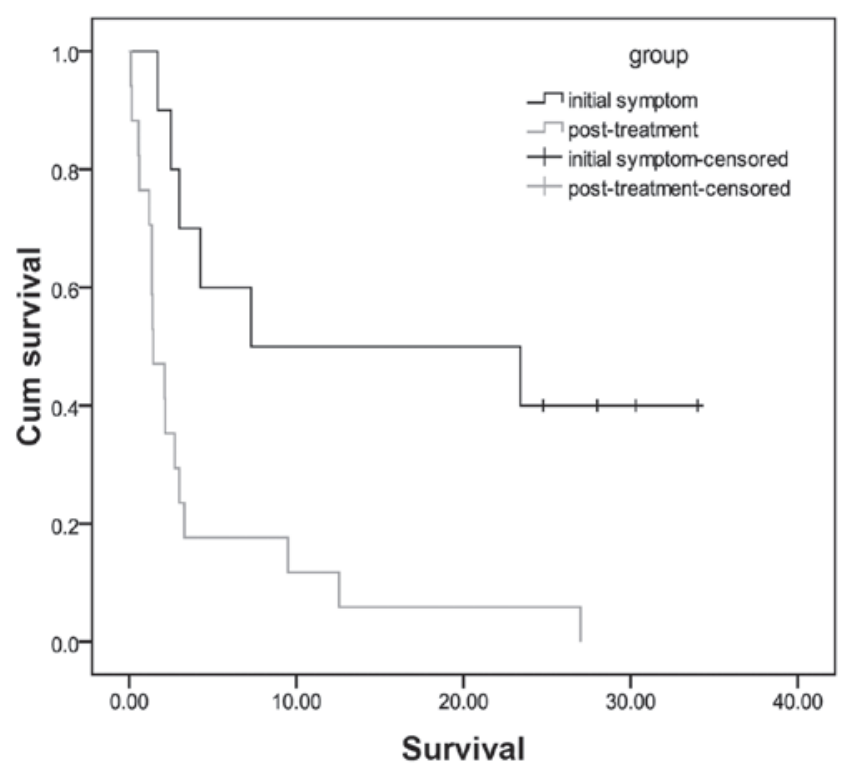

Figure 1. The overall survival time was significantly higher in the initial symptom compared with that of the post-treatment of primary cancer group $(\mathrm{P}=0.003)$. Sig., significance; cum, cumulative; df, degree of freedom.

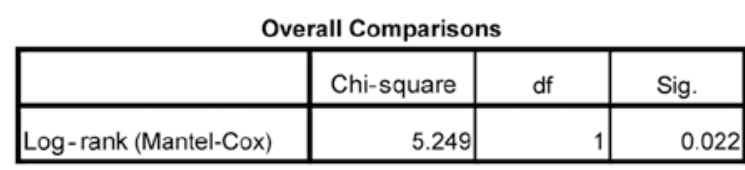

Test of equality of survival distributions for the different levels of group.

\section{Survival functions}

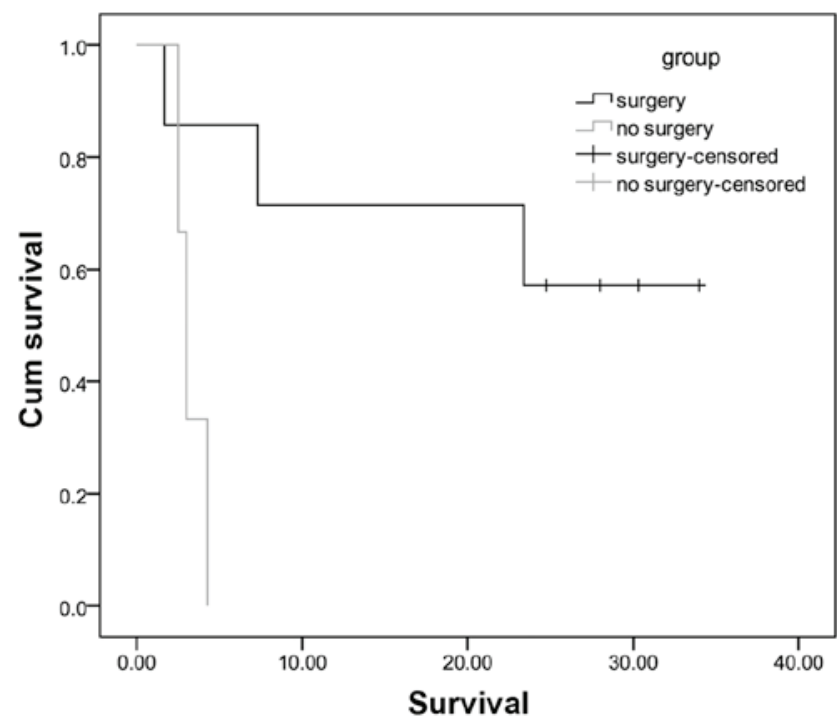

Figure 2. The overall survival time of patients who underwent surgery was significantly higher compared with the patients who did not receive surgical treatment $(\mathrm{P}=0.022)$. Sig., significance; cum, cumulative; df, degree of freedom. 
Table II. Malignant bowel obstruction as the initial symptom.

\begin{tabular}{|c|c|c|c|c|c|c|c|c|}
\hline $\begin{array}{l}\text { Case } \\
\text { no. }\end{array}$ & Gender & $\begin{array}{l}\text { Age } \\
\text { (years) }\end{array}$ & $\begin{array}{l}\text { Primary } \\
\text { cancer }\end{array}$ & Stage & Treatment & $\begin{array}{l}\text { Survival time } \\
\text { (months) }\end{array}$ & $\begin{array}{l}\text { ECOG score } \\
\text { (peri-treatment) }\end{array}$ & $\begin{array}{l}\text { Hospice } \\
\text { (days) }\end{array}$ \\
\hline 4 & M & 73 & Colon & IV & $\begin{array}{l}\text { Exp. lap. with Hartmann's, end } \\
\text { S-colostomy and wedge of seg } 2\end{array}$ & 30.3 & 2 to 1 & - \\
\hline 5 & M & 76 & S-colon & IV & $\begin{array}{l}\text { Colostomy + CPT-11, Erbitux, } \\
\text { UFUR, Oxalip, 5-FU }\end{array}$ & 23.4 & 3 to 2 & - \\
\hline 9 & F & 92 & R-S colon & II & Exp. lap. with T-loop colostomy & 1.7 & 4 to 4 & - \\
\hline 11 & $\mathrm{~F}$ & 81 & R-colon & IIIc & Exp. lap. with Hartmann's & 28 & 2 to 1 & - \\
\hline 12 & M & 81 & S-colon & IIIb & AR and protective T-loop colostomy & 7.3 & 2 to 1 & 8 \\
\hline 15 & M & 45 & Stomach & IV & Oxalip + HDFL $(8)^{\mathrm{b}}$ & 4.26 & 4 to 4 & - \\
\hline 17 & $\mathrm{~F}$ & 83 & D-colon & $\mathrm{IIb}$ & $\begin{array}{l}\text { T-loop colostomy and left } \\
\text { hemicolecotmy + UFUR, Xeloda }\end{array}$ & 24.76 & 2 to 1 & - \\
\hline 19 & M & 81 & S-colon & IIIB & $\begin{array}{l}\text { Exp. lap. with AR + 5-FU }(4)^{\mathrm{b}} \text {, } \\
\text { Oxalip + 5-FU }(2)^{\mathrm{b}}\end{array}$ & 34 & 2 to 1 & - \\
\hline 20 & $\mathrm{~F}$ & 74 & Duodenum & IV & 5-FU $(10)^{\mathrm{b}}$ & 3 & 4 to 4 & - \\
\hline 22 & F & 55 & Colon & IV & $\begin{array}{l}\text { HDFL }(2)^{\mathrm{b}}, \text { Oxalip }+\operatorname{HDFL}(2)^{\mathrm{b}} \text {, } \\
\text { Erbitux, Xeloda and CPT-11 }\end{array}$ & 2.5 & 3 to 4 & - \\
\hline
\end{tabular}

${ }^{a}$ Time from initial diagnosis of primary cancer with malignant bowel disease to death. ${ }^{\mathrm{b}}$ Courses of chemotherapy. ECOG, Eastern Cooperative Oncology Group; M, male; F, female; S, sigmoid; R, rectum; D, descending; exp. lap., exploratory laparotomy; UFUR, tegafur-uracil; 5-FU, 5-fluorouracil; HDFL, high-dose 5-FU and leucovorin; AR, anterior resection.

compared with that of the patients who received surgery alone or conservative treatment (2.72 vs. 0.69 months, respectively; $\mathrm{P}=0.018$, Fig. 3) and the patients' functional status exhibited a more significant improvement in the former group (ECOG score from 4 to 3 ). The mean survival time of gastric cancer patients receiving targeted therapy + chemotherapy was longer compared with those receiving chemotherapy alone, although the difference was not statistically significant $(\mathrm{P}=0.182)$, which may be due to the smaller number of cases. We also observed that cancers which responded well to chemotherapy, such as ovarian and colorectal cancers, were associated with longer survival.

Hospice patients. The clinical characteristics of MBO patients under hospice care are summarized in Table IV. A total of 7 patients received hospice care. The MBO symptoms in the terminal stage of cancer were intractable abdominal pain, abdominal fullness, nausea, vomiting and constipation. Under hospice care, the pain scores of all 7 patients decreased and the symptoms causing discomfort were improved.

\section{Discussion}

MBO is a common palliative care problem, encountered in $5-51 \%$ of patients with ovarian cancer, $10-28 \%$ of patients with colorectal cancer and $3-15 \%$ of patients with other types of cancer $(1,2,5-8)$. In our study, the type of cancer most commonly responsible for $\mathrm{MBO}$ was found to be colorectal adenocarcinoma (55\%). The differences in incidence may be attributed to the differences in clinical environment, admission criteria, diagnostic standards and clinical assessment.

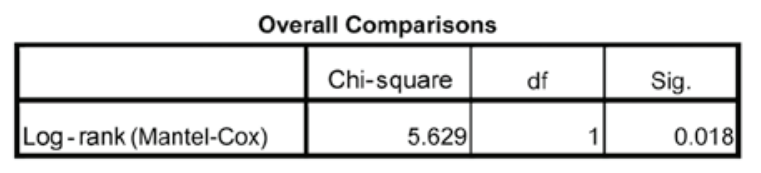

Test of equality of survival distributions for the different levels of group.

\section{Survival functions}

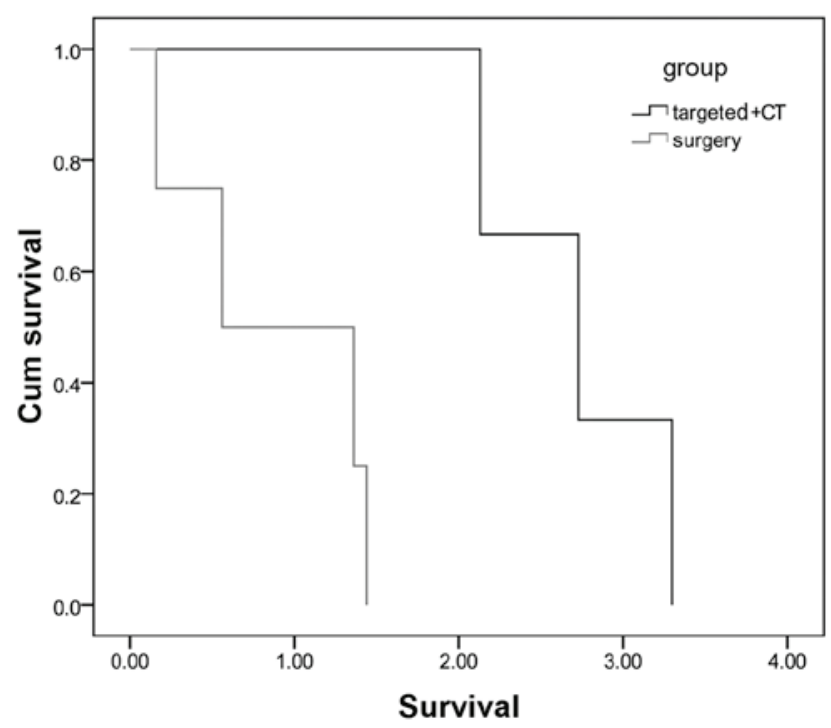

Figure 3. The mean survival time of colorectal cancer patients who received targeted therapy and chemotherapy (CT) was longer compared with those receiving surgery alone or conservative treatment ( 2.72 vs. 0.69 months, $\mathrm{P}=0.018)$ and their functional status exhibited a more significant improvement (ECOG score from 4 to 3). Sig., significance; cum, cumulative; df, degree of freedom. 
Table III. Post-treatment malignant bowel obstruction (MBO).

\begin{tabular}{|c|c|c|c|c|c|c|c|c|c|}
\hline $\begin{array}{l}\text { Case } \\
\text { no. }\end{array}$ & Gender & $\begin{array}{c}\text { Age } \\
\text { (years) }\end{array}$ & $\begin{array}{l}\text { Primary } \\
\text { cancer }\end{array}$ & Stage & Treatment & $\begin{array}{l}\mathrm{MBO} \\
\text { treatment }\end{array}$ & $\begin{array}{l}\text { Survival } \\
\text { time } \\
\text { (months) }\end{array}$ & $\begin{array}{c}\text { ECOG } \\
\text { score } \\
(\mathrm{Tx})\end{array}$ & $\begin{array}{l}\text { Hospice } \\
\text { (days) }\end{array}$ \\
\hline 1 & $\mathrm{~F}$ & 81 & R-colon & III & $\mathrm{APR}+$ colostomy $+\mathrm{CCRT}$ & $\begin{array}{l}\text { Exp. lap. with loop } \\
\text { jejunostomy }\end{array}$ & 1.44 & 4 to 4 & - \\
\hline 2 & M & 85 & Colon & IV & Nil & Nil & 0.56 & 4 to 4 & 17 \\
\hline 3 & $\mathrm{~F}$ & 69 & $\mathrm{TCC}$ & III & $\begin{array}{l}\text { Nephroureterectomy }+ \\
\text { removal of bladder cuff, } \\
\text { R't+CCRT (Toxol weekly) }\end{array}$ & $\begin{array}{l}\text { Gemzar + vinblastin; } \\
\text { MTX + vinblastin }\end{array}$ & 1.2 & 4 to 4 & - \\
\hline 6 & $\mathrm{~F}$ & 64 & Ovary & IIIc & $\begin{array}{l}\text { Debulking+Phyxol+ } \\
\text { carboplatin+Doxil, } \\
\text { Caelyx+Hycamptin }\end{array}$ & $\begin{array}{l}\text { Carboplatin }(11)^{\mathrm{a}}+ \\
\text { Hycamptin }(2)^{\mathrm{a}}\end{array}$ & 12.56 & 2 to 1 & 60 \\
\hline 7 & $\mathrm{~F}$ & 46 & Stomach & IV & Cisplatin $+5-\mathrm{FU}$ & $5-\mathrm{FU}(3)^{\mathrm{a}}$ & 3 & 4 to 3 & 9 \\
\hline 8 & M & 36 & D-S colon & III & $\begin{array}{l}\text { Exp. lap. with bisegmente- } \\
\text { ctomy, left hemicolectomy }\end{array}$ & $\begin{array}{l}\text { 5-FU(5) }{ }^{\mathrm{a}} ; \text { Oxalip }+ \\
\text { 5-FU }(2)^{\mathrm{a}} ; \text { Erbitux }(8)^{\mathrm{a}}\end{array}$ & 3.3 & 4 to 3 & - \\
\hline 10 & M & 72 & Duodenum & II & Whipple resection+5-FU $(11)^{\mathrm{a}}$ & conservative & 0.1 & 4 to 4 & - \\
\hline 13 & M & 66 & Stomach & IV & HDFU (4) $)^{\mathrm{a}}$ & Taxotere $(1)^{\mathrm{a}}$ & 1.4 & 4 to 4 & 18 \\
\hline 14 & M & 67 & R-S colon & IIa & $\begin{array}{l}\text { Neoadjuvant CCRT, s/p oral } \\
\text { UFUR+exp. lap. with LAR }\end{array}$ & Nil & 0.16 & 4 to 4 & - \\
\hline 16 & M & 77 & $\begin{array}{l}\text { Pseudomyxo- } \\
\text { ma peritonei }\end{array}$ & & $\begin{array}{l}\text { Exp. lap. with removal } \\
\text { of tumor }\end{array}$ & Nil & 0.6 & 4 to 4 & - \\
\hline 18 & M & 84 & Colon & IIB & $\begin{array}{l}\text { Op+LDFL and liver metasta- } \\
\text { sis s/p weekly HDFL, Campto } \\
\text { with HDFL, Oxalip with } \\
\text { HDFL, Erbitux with HDFL }\end{array}$ & Xeloda, Erbitux & 2.73 & 4 to 3 & 16 \\
\hline 21 & M & 70 & T-colon & IIIc & $\begin{array}{l}\text { Right hemicolectomy+5-FU } \\
+ \text { Eloxatin ( } 6 \text { months) }\end{array}$ & FOLFORI $(4)^{\mathrm{a}}$ & 2.13 & 4 to 3 & - \\
\hline 23 & M & 71 & S-colon & IV & $\begin{array}{l}\text { Hartmann's procedure and } \\
\text { lobectomy of liver }\end{array}$ & Nil & 1.36 & 4 to 4 & 23 \\
\hline 24 & $\mathrm{~F}$ & 46 & Stomach & IV & Exp. lap.+TAH+BSO, & $5-\mathrm{FU}$ & 2.16 & 4 to 3 & - \\
\hline 25 & M & 57 & Pancreas & IV & Major surgery & $5-\mathrm{FU}$ & 9.5 & 2 to 1 & - \\
\hline 26 & M & 63 & TCC & IV & $\begin{array}{l}\text { Nephroureterectomy and } \\
\text { removal of bladder cuff, R't }\end{array}$ & $\begin{array}{l}\text { Exp. lap. with } \\
\text { lysis of adhesions } \\
\text { +jejunojejunostomy } \\
\text { +end ileostomy } \\
\text { +decompression } \\
\text { of small intestine }\end{array}$ & 1.36 & 4 to 4 & - \\
\hline 27 & $\mathrm{~F}$ & 78 & Stomach & IV & $\begin{array}{l}\text { Subtotal gastrectomy } \\
+ \text { FOLFOX }\end{array}$ & $\begin{array}{l}\text { AR+colostomy, } \\
\text { HDFL; Phyxol+ } \\
\text { Avastin; Irino+ } \\
\text { HDFL+Avastin, } \\
\text { with daily oral UFUR }\end{array}$ & 27 & 4 to 2 & - \\
\hline
\end{tabular}

a'Courses of chemotherapy. ECOG, Eastern Cooperative Oncology Group; Tx, the ECOG status of the patient; M, male; F, female; S, sigmoid; R, rectum; D, descending; T, transverse; APR, abdominoperineal resection; CCRT, concurrent chemoradiation; exp. lap., exploratory laparotomy; Nil, conservative treatment; TCC, transitional cell carcinoma; MTX, methotrexate; R't, radiotherapy; s/p, status post; UFUR, tegafur-uracil; Op, operation; 5-FU, 5-fluorouracil; HDFU, high-dose 5-FU; LDFL, low-dose 5-FU and leucovorin; HDFL, high-dose 5-FU and leucovorin; TAH, total abdominal hysterectomy; BSO, bilateral salpingo-oophorectomy; AR, anterior resection; LAR, low anterior resection; FOLFOX, leucovorin, 5-FU and oxaliplatin; FOLFORI, irinotecan, infusional 5-FU and high-dose leucovorin.

Although $\mathrm{MBO}$ is a common problem in clinical practice, achieving a consensus on its management is difficult, as the treatment selection maybe be affected by the location and degree of obstruction, cancer stage, patient's functional status, survival time and co-morbidity (2,5-8). Furthermore, it may also be affected by the lack of a definitive diagnosis, 
Table IV. Palliative care of malignant bowel obstruction.

\begin{tabular}{|c|c|c|c|c|c|c|c|c|c|c|}
\hline $\begin{array}{l}\text { Case } \\
\text { no. }\end{array}$ & Gender & Age & $\begin{array}{c}\text { Primary } \\
\text { cancer }\end{array}$ & Stage & Symptoms & $\begin{array}{c}\text { ECOG } \\
\text { (hospice) }\end{array}$ & Pain & TPN & NG & $\begin{array}{c}\text { Hospice } \\
\text { (days) }\end{array}$ \\
\hline 12 & M & 81 & S-colon & $\mathrm{IIIb}$ & Abdominal fullness, nausea and vomiting & 4 & 9 to 4 & $\mathrm{~N}$ & $\mathrm{Y}$ & 8 \\
\hline 2 & M & 85 & Colon & IV & Abdominal fullness & 4 & 6 to 2 & $\mathrm{~N}$ & $\mathrm{~N}$ & 17 \\
\hline 6 & $\mathrm{~F}$ & 64 & Ovary & IIIc & Abdominal fullness, nausea and vomiting & 3 & 5 to 3 & $\mathrm{~N}$ & $\mathrm{~N}$ & 60 \\
\hline 7 & $\mathrm{~F}$ & 46 & Stomach & IV & Constipation and shortness of breath & 4 & 6 to 2 & $\mathrm{~N}$ & $\mathrm{Y}$ & 9 \\
\hline 13 & M & 66 & Stomach & IV & Abdominal fullness and constipation & 4 & 7 to 4 & $\mathrm{~N}$ & $\mathrm{Y}$ & 18 \\
\hline 18 & M & 84 & Colon & IIB & Abdominal fullness & 4 & 5 to 3 & $\mathrm{~N}$ & $\mathrm{Y}$ & 16 \\
\hline 23 & M & 71 & S-colon & IV & Abdominal pain and fullness & 3 & 3 to 2 & $\mathrm{~N}$ & $\mathrm{Y}$ & 23 \\
\hline
\end{tabular}

ECOG, Eastern Cooperative Oncology Group; S, sigmoid; TPN, total parenteral nutrition; NG, nasogastric tube; M, male; F, female; N, no; Y, yes.

therapeutic goals and large clinical studies assessing the effects of different treatment plans on symptom relief and QOL improvement.

MBO patients may be classified into IS and PT groups according to the time of onset of the MBO symptoms and the patients of the IS group were considered more suitable for surgery, exhibited better ECOG scores and longer mean survival time compared with those in the PT group.

Woolfson et al demonstrated in a non-randomized study in 1997 that surgery did not significantly affect survival time and QOL (9). However, in our study, the overall survival time of the patients in the IS group who received surgical treatment was significantly longer compared with that of the no surgical treatment group. Thus, our results suggested that surgical treatment is suitable for IS group patients.

In the PT group, the mean survival time of colorectal cancer patients who received targeted therapy and chemotherapy was longer compared with that of patients who received surgery alone or conservative treatment and the patients' functional status exhibited a more significant improvement in the former group. Thus, palliative chemotherapy may be of value for this group of patients and may be considered a viable option when discussing the therapeutic plan with the patient and the family members.

The most common symptoms of $\mathrm{MBO}$ in the terminal stages of cancer are intractable abdominal pain, abdominal fullness, nausea, vomiting and constipation. Previous studies have predominantly focused on approaches to the management and resolution of intestinal obstruction, with little consideration for QOL (10). Under palliative care, the pain scores exhibit a marked decrease and the symptoms are improved. Thus, medical care personnel are always questioned regarding hospice care interventions in terminal cancer patients.

Multimodality treatment strategies, which currently include surgical treatment, palliative radiotherapy, chemotherapy and total parenteral nutrition formulas, may be used to relieve the symptoms in patients with $\mathrm{MBO}$; however, there is no consensus regarding the optimal treatment strategy and no strong evidence supporting the efficacy of any treatment in improving QOL and prolonging survival. Thus, it is crucial for physicians in palliative care to accurately assess the patient's clinical condition, anticipated survival time, risk of mortality and morbidity. The physicians should also communicate with the patient and the family members prior to making therapeutic plan decisions. Furthermore, educational interventions for patients and their family members should focus on the primary goals of $\mathrm{MBO}$ management in the palliative care setting. Patients with MBO from metastastic intra-abdominal disease may bear a significant physical and psychological burden, with a highly compromised QOL at the time of diagnosis; however, with adequate treatment, an improvement may be quickly achieved.

Targeted therapy for prolonging survival requires further investigations. Our previous studies have had certain limitations, such as limited number of cases, lack of QOL evaluation, heterogeneity, different types of cancer and different forms of treatment (11).

There were also important limitations to the present study. Although this was not a randomized trial, the patient characteristics in the two groups were significantly different. Furthermore, the number of patients and duration of follow-up were limited. A longer follow-up period may help stabilize the trends and enable more reliable conclusions.

In conclusion, the primary cause of MBO in our study was adenocarcinoma of the colon. The overall survival time was significantly higher in the IS group and improved QOL was achieved in patients receiving surgical treatment. The mean survival time of colorectal cancer patients receiving targeted therapy and chemotherapy was longer compared with those receiving surgery alone or conservative treatment and their functional status exhibited a more significant improvement. In addition, for end-stage cancer patients with MBO, hospice care was effective in reducing pain scores and relieving the symptoms of the disease.

\section{Acknowledgements}

This study was supported by a grant from Tri-Service General Hospital (no. TSGH-C100-177), Taiwan, R.O.C.

\section{References}

1. Ripamonti $\mathrm{C}$ and Mercadante S: Pathophysiology and management of malignant bowel obstruction. In: Oxford Textbook of Palliative Medicine. Doyle D, Hanks G, Cherny NI and Calman K (eds). 3rd edition. New York Oxford University Press, NY, pp496-507, 2004. 
2. Ripamonti CI, Easson AM and Gerdes H: Management of malignant bowel obstruction. Eur J Cancer 44: 1105-1115, 2008.

3. Kaplan EL and Meier P: Nonparametric estimation from incomplete observations. J Am Stat Assoc 53: 457-481, 1958.

4. Peto R and Pike MC: Conservatism of the approximation sigma (O-E)2-E in the logrank test for survival data or tumor incidence data. Biometrics 29: 579-584, 1973.

5. Weber $\mathrm{C}$ and Zulian GB: Malignant irreversible intestinal obstruction: the powerful association of octreotide to corticosteroids, antiemetics, and analgesics. Am J Hosp Palliat Care 26: 84-88, 2009.

6. Wong TH and Tan YM: Surgery for the palliation of intestinal obstruction in advanced abdominal malignancy. Singapore Med J 50: 1139-1144, 2009.

7. Davis MP and Nouneh C: Modern management of cancer-related intestinal obstruction. Curr Oncol Rep 2: 343-350, 2000.
8. Selby D, Wright F, Stilos K, et al: Room for improvement? A quality-of-life assessment in patients with malignant bowel obstruction. Palliat Med 24: 38-45, 2011.

9. Sun A. Bae K, Gore EM, et al: Phase III trial of prophylactic cranial irradiation compared with observation in patients with locally advanced non-small-cell lung cancer: neurocognitive and quality-of-life analysis. J Clin Oncol 29: 279-286, 2011.

10. Thaker DA, Stafford BC adn Gaffney LS: Palliative management of malignant bowel obstruction in terminally ill patient. Indian $\mathrm{J}$ Palliat Care 16: 97-100, 2010.

11. Chouliara Z, Kearney N, Stott D, Molassiotis A and Miller M: Perceptions of older people with cancer of information, decision making and treatment: a systemic review of selected literature. Ann Oncol 15: 1596-1602, 2004 